\title{
Infrared Spectroscopy for the Quality Assessment of Habanero Chilli: A Proof-of-Concept Study ${ }^{\dagger}$
}

\author{
Joel B. Johnson * ${ }^{\mathbb{D}}$, Janice S. Mani and Mani Naiker
}

check for

updates

Citation: Johnson, J.B.; Mani, J.S.; Naiker, M. Infrared Spectroscopy for the Quality Assessment of Habanero Chilli: A Proof-of-Concept Study. Eng. Proc. 2021, 8, 19. https://doi.org/ 10.3390/engproc2021008019

Academic Editors: Giovanni Ferrarini, Paolo Bison and Gianluca Cadelano

Published: 23 November 2021

Publisher's Note: MDPI stays neutral with regard to jurisdictional claims in published maps and institutional affiliations.

Copyright: (c) 2021 by the authors. Licensee MDPI, Basel, Switzerland. This article is an open access article distributed under the terms and conditions of the Creative Commons Attribution (CC BY) license (https:/ / creativecommons.org/licenses/by/ $4.0 /)$.
School of Health, Medical \& Applied Sciences, Central Queensland University, Bruce Hwy, North Rockhampton, QLD 4701, Australia; janice.mani@gmail.com (J.S.M.); m.naiker@cqu.edu.au (M.N.)

* Correspondence: joel.johnson@cqumail.com

+ Presented at the 16th International Workshop on Advanced Infrared Technology \& Applications, 26-28 October 2021; Available online: https: / / aita2021.sciforum.net/.

\begin{abstract}
Habanero chillies (Capsicum chinense cv Habanero) are a popular species of hot chilli in Australia, with their production steadily increasing. However, there is limited research on this crop due to its relatively low levels of production at present. Rapid methods of assessing fruit quality could be greatly beneficial both for quality assurance purposes and for use in breeding programs or experimental growing trials. Consequently, this work investigated the use of infrared spectroscopy for predicting dry matter content, total phenolic content and capsaicin/dihydrocapsaicin content in 20 Australian Habanero chilli samples. Near-infrared spectra (908-1676 nm) taken from the fresh fruit showed strong potential for the estimation of dry matter content, with an $\mathrm{R}^{2}{ }_{\mathrm{cv}}$ of 0.65 and standard error of cross-validation (SECV) of $0.50 \%$. A moving-window partial least squares regression model was applied to optimise the spectral window used for dry matter content prediction, with the bestperforming window being between 1224 and $1422 \mathrm{~nm}$. However, the near-infrared spectra could not be used to estimate the total phenolic content or capsaicin/dihydrocapsaicin content of the samples. Mid-infrared spectra (4000-400 $\mathrm{cm}^{-1}$ ) collected from the dried, powdered material showed slightly more promise for the prediction of total phenolics and the ratio of capsaicin-to-dihydrocapsaicin, with an $\mathrm{R}^{2}$ cv of 0.45 and SECV of 0.32 for the latter. The results suggest that infrared spectroscopy may be able to determine dry matter content in Habanero chilli with acceptable accuracy, but not the capsaicinoid or total phenolic content.
\end{abstract}

Keywords: total phenolics; capsaicinoids; Capsicum chinense cv Habanero; mid-infrared spectroscopy (MIRS); near-infrared spectroscopy (NIRS)

\section{Introduction}

Habanero chillies (Capsicum chinense cv Habanero) are some of the hottest commonly consumed chillies in Australia. The pungency of chilli arises from capsaicinoids, which are compounds classified as $N$-vanillylamides of branched fatty acids. The two most abundant capsaicinoids present in chilli are capsaicin and dihydrocapsaicin; however, a number of other capsaicinoids may be present in minor amounts. There is an ongoing interest in developing new Habanero chilli varieties with higher capsaicin contents, as these form a niche high-value market sector.

Capsaicinoid contents are generally measured using high-performance liquid chromatography (HPLC), which provides a high level of specificity and accuracy. However, this technique is time-consuming and expensive, which means that it may not be suitable for the routine assessment of large number of samples. Hence, there is recent interest in using rapid analytical techniques such as infrared spectroscopy for the quality assurance/analysis of chilli. Near-infrared (NIR) spectroscopy has previously been used for the estimation of capsaicinoid content [1] and total phenolic content in chilli [2]. Furthermore, NIR spectroscopy has an extensive history of use for food quality analysis [3,4]. Hence, 
this study aimed to conduct a proof-of-concept investigation into the potential application of infrared spectroscopy for the quality analysis of Habanero chilli and to compare the relative performance of NIR and mid-infrared (MIR) spectroscopy for this purpose.

\section{Methods}

Twenty samples of Habanero chilli were sourced from Austchilli (Bundaberg, Queensland), incorporating a wide range of environmental variability. Near-infrared spectra between 908 and $1676 \mathrm{~nm}$ were collected from the fresh, intact chillies using a MicroNIR OnSite handheld spectrometer (Viavi, Santa Rosa, CA, USA). Duplicate spectra were collected from opposite sides of each chilli, providing four spectra per sample ( $\mathrm{n}=80$ spectra in total). The chillies were subsequently oven-dried and ground to a fine powder. Mid-infrared spectra were collected from the dried, ground chilli powder in triplicate using a Bruker Alpha Fourier transform infrared (FTIR) spectrophotometer (Ettlingen, Germany) fitted with an attenuated total reflectance (ATR) module (4000-400 $\mathrm{cm}^{-1}$ ). Polar compounds were extracted from the dried, powdered samples in duplicate using $90 \%$ methanol, following previously described protocols [5]. The total phenolic (TP) content of the extracts was measured as previously reported for other matrices [5], with the results being expressed as gallic acid equivalents (GAE) per $100 \mathrm{~g}$ (dry weight basis). Capsaicin and dihydrocapsaicin contents were analysed in the methanolic extracts using HPLC, following the method of Waite and Aubin [6]. Chemometric analysis was performed in the Unscrambler X software (version 10; Camo Analytics; Oslo, Norway). Moving-window PLS-R was conducted using a custom script in R Studio running R 4.0.2.

\section{Results and Discussion}

Figure 1 shows the NIR spectra of the chilli samples. The major peaks were centred at approximately 1447, 1193 and $976 \mathrm{~nm}$, corresponding to the $\mathrm{OH}$ second overtone, $\mathrm{CH}_{3}$ second overtone and $\mathrm{OH}$ third overtone, respectively. Following Standard Normal Variate $(\mathrm{SNV})$ normalisation, two of the spectra were identified as outliers and removed.

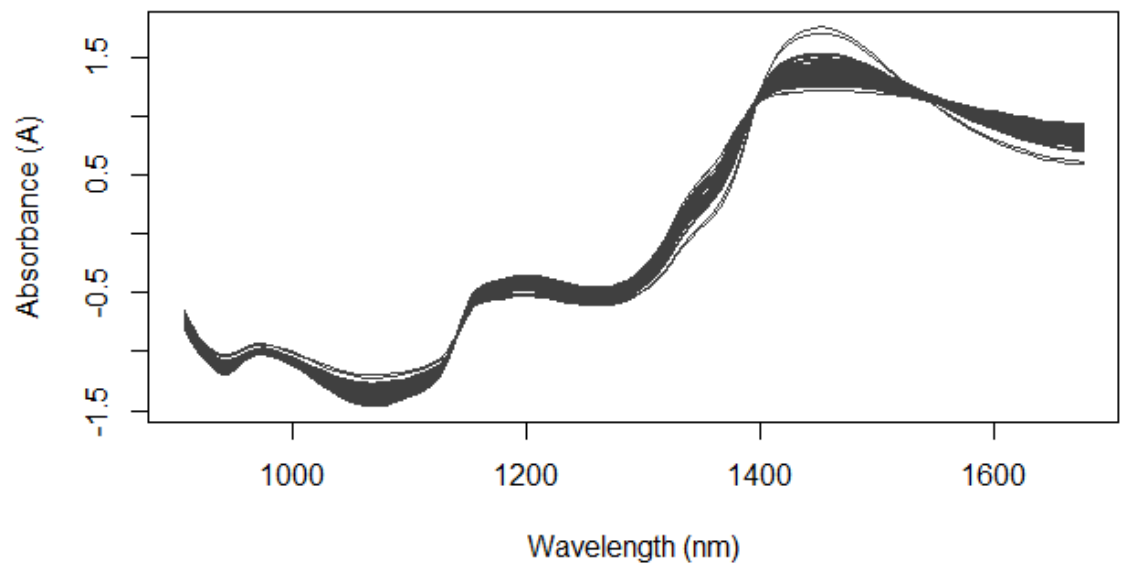

Figure 1. NIR spectra (908-1676 nm) of the Habanero chilli samples following SNV smoothing.

As can be seen in Table 1, only the prediction of dry matter gave acceptable model statistics when using the NIR spectra, with an $\mathrm{R}^{2}{ }_{\mathrm{cv}}$ of 0.65 and standard error of crossvalidation (SECV) of $0.50 \%$. The comparison of results obtained using NIR spectroscopy and the reference DM method is presented in Figure 2. Although the model statistics could be further improved, these results suggest that NIR spectroscopy may be useful for the rapid, in-field estimation of dry matter content. This could be used to monitor the maturity of the chilli crop and determine the optimum time for harvest. However, PLS-R prediction of other parameters showed poor $\mathrm{R}^{2}$ val values and high SECV values, indicating that the NIR spectral range used was not able to detect the functional groups responsible for these compound classes (i.e., total phenolics, capsaicinoids). 
Table 1. Optimum model statistics for the prediction of various parameters in Habanero chilli using the full NIR spectra (908-1676 nm) with different spectral pre-processing methods ( $\mathrm{n}=78$ spectra).

\begin{tabular}{cccccccc}
\hline Parameter & Spectral Pre-Processing & Factors & $\mathbf{R}^{2}{ }_{\text {cal }}$ & SEC & $\mathbf{R}^{2}{ }_{\text {val }}$ & SECV & $\mathbf{R P D}$ \\
\hline $\mathrm{DM}$ & $\mathrm{SNV}+1 \mathrm{~d} 5$ & 5 & 0.70 & 0.44 & 0.65 & 0.50 & 2.02 \\
\hline $\mathrm{TP}$ & $\mathrm{SNV}+2 \mathrm{~d} 11$ & 3 & 0.29 & 152 & 0.21 & 162 & 1.14 \\
\hline Capsaicin & $\mathrm{SNV}$ & 2 & 0.19 & 589 & 0.15 & 611 & 1.08 \\
\hline Dihydrocapsaicin & $\mathrm{SNV}+1 \mathrm{~d} 11$ & 7 & 0.57 & 171 & 0.36 & 215 & 1.05 \\
\hline Capsaicin-to-dihydrocapsaicin ratio & $\mathrm{SNV}+1 \mathrm{~d} 5$ & 7 & 0.48 & 0.31 & 0.28 & 0.36 & 1.19 \\
\hline Sum capsaicinoids & $\mathrm{SNV}+1 \mathrm{~d} 5$ & 2 & 0.21 & 767 & 0.15 & 811 & 1.08 \\
\hline Pungency (SHU) & $\mathrm{SNV}+1 \mathrm{~d} 11$ & 2 & 0.20 & 12,380 & 0.15 & 12,887 & 1.09 \\
\hline
\end{tabular}

One outlier sample ( $\mathrm{n}=4$ spectra) was excluded.

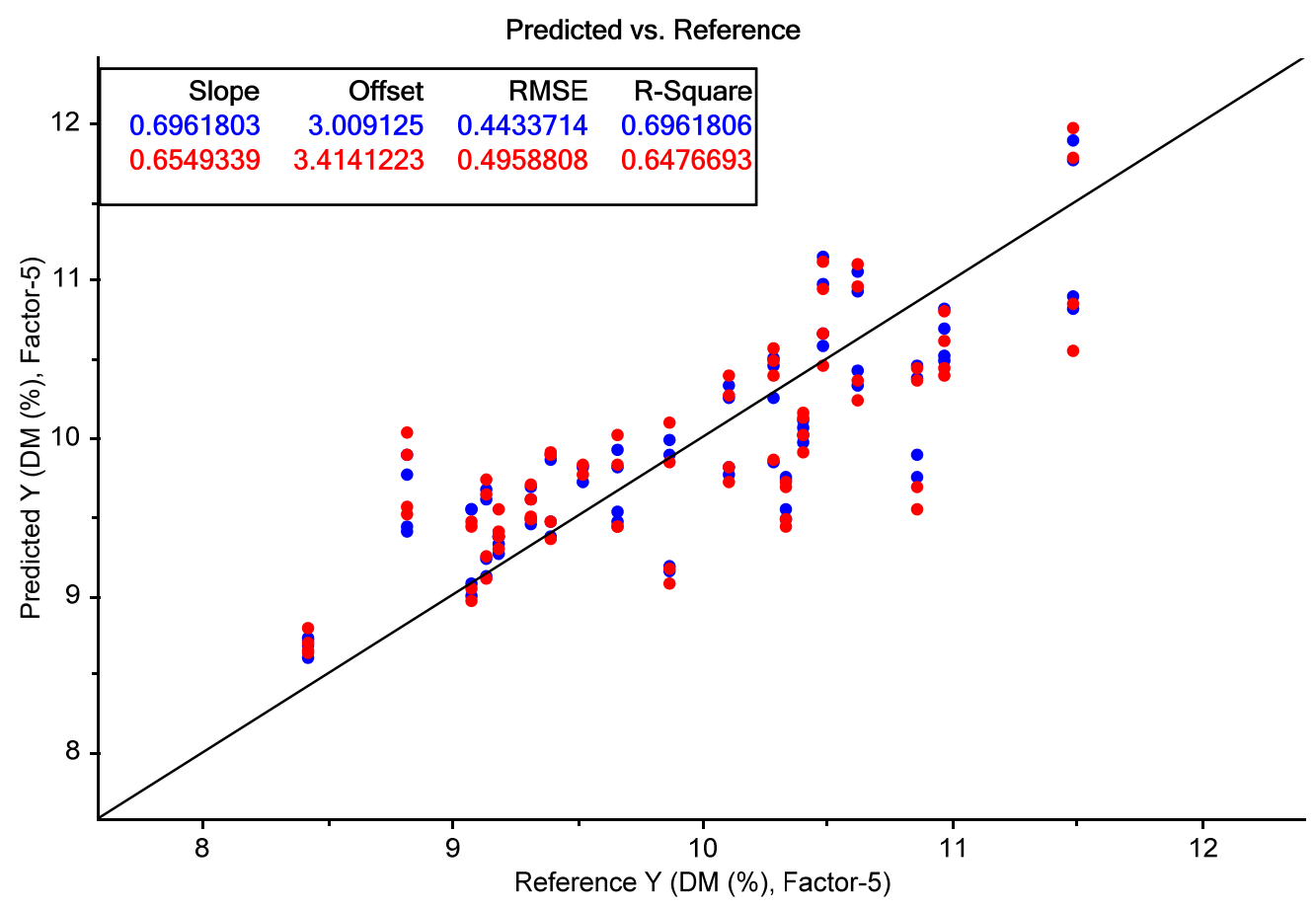

Figure 2. Calibration (blue) and cross-validation (red) results for the prediction of dry matter content in Habanero chilli using NIR spectroscopy.

Moving-window PLS-R was implemented to determine the optimum range of wavelengths to use for the prediction of dry matter content, following the method of Anderson et al. [7]. The procedure used the SNV+1d5 pre-processed spectra, with a step increment of $6 \mathrm{~nm}$ throughout the NIR spectrum. The optimum model was found between wavelengths of 1224 and $1422 \mathrm{~nm}$, with an $\mathrm{R}^{2}$ val of 0.67 , RMSECV of $0.46 \%$ and RPD of 2.20 .

As shown in Table 2, the model performance for all parameters aside from dry matter was slightly higher when using MIR compared to NIR spectra; nevertheless, model performance remained quite poor. The best performing MIR model was for the capsaicinto-dihydrocapsaicin ratio, which showed an $\mathrm{R}^{2}$ val of 0.45 , SECV of 0.32 and RPD of 1.34 . 
Table 2. Optimum model statistics for the prediction of various parameters in Habanero chilli using the full MIR spectra (4000-400 $\mathrm{cm}^{-1}$ ) with different spectral pre-processing methods ( $\mathrm{n}=60$ spectra).

\begin{tabular}{cccccccc}
\hline Parameter & Spectral Pre-Processing & Factors & $\mathbf{R}^{2}{ }_{\text {cal }}$ & SEC & $\mathbf{R}^{2}{ }_{\text {val }}$ & SECV & $\mathbf{R P D}$ \\
\hline $\mathrm{DM}$ & $\mathrm{SNV}+1 \mathrm{~d} 11$ & 5 & 0.75 & 0.50 & 0.28 & 0.86 & 1.17 \\
\hline $\mathrm{TP}$ & $2 \mathrm{~d} 11$ & 7 & 0.93 & 48 & 0.37 & 145 & 1.28 \\
\hline Capsaicin & $\mathrm{SNV}+2 \mathrm{~d} 11$ & 6 & 0.91 & 196 & 0.35 & 530 & 1.25 \\
\hline Dihydrocapsaicin & $1 \mathrm{~d} 21$ & 7 & 0.77 & 127 & 0.29 & 222 & 1.02 \\
\hline Capsaicin-to-dihydrocapsaicin ratio & $\mathrm{SNV}+1 \mathrm{~d} 11$ & 6 & 0.84 & 0.17 & 0.45 & 0.32 & 1.34 \\
\hline Sum capsaicinoids & $\mathrm{SNV}+2 \mathrm{~d} 11$ & 6 & 0.90 & 268 & 0.31 & 722 & 1.21 \\
\hline Pungency (SHU) & $\mathrm{SNV}+1 \mathrm{~d} 11$ & 7 & 0.88 & 4715 & 0.32 & 11,348 & 1.24 \\
\hline
\end{tabular}

\section{Conclusions}

This proof-of-concept study sought to investigate the potential of NIR and MIR spectroscopy towards the rapid quality assessment of Habanero chillies, including the prediction of dry matter content, total phenolic content and capsaicin/dihydrocapsaicin content. Spectra collected using a handheld NIR instrument showed strong potential for the estimation of DM content, but not for TP or capsaicinoid content. The major benefits of using handheld instrumentation include portability, speed of measurement (almost instantaneous) and low cost (virtually no ongoing costs). This means that NIR instrumentation could potentially be applied for use in the in-field assessment of fruit maturity. Furthermore, the method is non-destructive, meaning that samples can be analysed at different points throughout the harvest season to determine the optimum time for harvest. MIR spectroscopy did not perform well for the estimation of capsaicinoid content, although it performed slightly better for the estimation of TP content and the capsaicin-to-dihydrocapsaicin ratio.

Author Contributions: Conceptualization, J.B.J. and M.N.; methodology, J.B.J.; software, J.B.J.; validation, J.B.J.; formal analysis, J.B.J.; investigation, J.B.J., J.S.M.; resources, J.B.J., M.N.; data curation, J.B.J.; writing—original draft preparation, J.B.J.; writing-review and editing, J.B.J., J.S.M., M.N.; visualization, J.B.J.; super-vision, M.N.; project administration, M.N.; funding acquisition, M.N. All authors have read and agreed to the published version of the manuscript.

Funding: This work was supported in part by a New Staff Grant (RSH/5343) awarded by CQUniversity to one of the authors (M.N.). One of the authors (J.B.J.) acknowledges support from the Australian Government in the form of a Research Training Program.

Data Availability Statement: The data supporting the findings of this article are available upon request from the corresponding author.

Conflicts of Interest: The authors declare no conflict of interest.

\section{References}

1. Lim, J.; Kim, G.; Mo, C.; Kim, M.S. Design and Fabrication of a Real-Time Measurement System for the Capsaicinoid Content of Korean Red Pepper (Capsicum annuum L.) Powder by Visible and Near-Infrared Spectroscopy. Sensors 2015, 15, $27420-27435$. [CrossRef] [PubMed]

2. Toledo-Martín, E.M.; García-García, M.C.; Font, R.; Moreno-Rojas, J.M.; Gómez, P.; Salinas-Navarro, M.; Del Río-Celestino, M. Application of visible/near-infrared reflectance spectroscopy for predicting internal and external quality in pepper. J. Sci. Food Agric. 2016, 96, 3114-3125. [CrossRef] [PubMed]

3. De Marchi, M.; Penasa, M.; Zidi, A.; Manuelian, C.L. Invited review: Use of infrared technologies for the assessment of dairy products-Applications and perspectives. J. Dairy Sci. 2018, 101, 10589-10604. [CrossRef] [PubMed]

4. McGoverin, C.M.; Weeranantanaphan, J.; Downey, G.; Manley, M. Review: The Application of near Infrared Spectroscopy to the Measurement of Bioactive Compounds in Food Commodities. J. Near Infrared Spectrosc. 2010, 18, 87-111. [CrossRef]

5. Johnson, J.; Collins, T.; Skylas, D.; Quail, K.; Blanchard, C.; Naiker, M. Profiling the varietal antioxidative content and macrochemical composition in Australian faba beans (Vicia faba L.). Legume Sci. 2020, 2, e28. [CrossRef] 
6. Waite, M.S.; Aubin, A.J. A Modular HPLC System for Routine Analysis of Capsaicin from Hot Sauces; Waters Corporation: Milford, MA, USA, 2008; p. 5.

7. Anderson, N.T.; Walsh, K.B.; Subedi, P.P.; Hayes, C.H. Achieving robustness across season, location and cultivar for a NIRS model for intact mango fruit dry matter content. Postharvest Biol. Technol. 2020, 168, 111202. [CrossRef] 